Philosophy and Architecture, ed. M. Mitias (Amsterdam-Atlanta: Rodopi, 1994), pp.21-30. Re-printed in Arnold Berleant, Living in the Landscape (Lawrence: University Press of Kansas, 1997), pp. 113-124. ISBN 978-0700608119

\title{
ARCHITECTURE AND THE AESTHETICS OF CONTINUITY
}

\section{Architectural Tradition and Change}

Although architecture has long been practiced as an art, its acceptance as a fine art was only confirmed in the eighteenth century when the modern classification of the arts was finally decided. ${ }^{1}$ This was the same period in which modern aesthetics assumed its definitive form. Architecture was thus absorbed into the august body of the "fine" arts and was explained by the theory of art--the theory of those arts.

In many respects, architecture is a paradigm of art in the traditional sense. It offers singular objects of striking size and appearance that stand apart and dominate their surroundings. Such structures are often awe-inspiring, and their reverential power is transferred by association to the individuals and institutions identified with them. As an ideal and in practice, the tradition that honors monumentality and constructs edifices is what the popular mind associates with architecture, and this tradition continues to supply the paradigm to critics and scholars. Magnificence and power are taken to be the body and meaning of this art.

Such a model continues to serve us. Structures have grown more lofty and massive. Government buildings, becoming ever larger, continue the classical tradition of solid monumentality, and office towers have long since surpassed cathedrals in size and height. Unlike medieval cathedrals, which were squeezed in by neighboring shops and houses, skyscrapers often stand in grand isolation in their own plazas. And as their size and implicit power have grown, so has the homage they inspire. Such buildings, vying 
with one another for supremacy of mass and height, represent the continuing tradition of architecture as edifice.

Yet architecture has also assimilated many other currents of style, thought, and role. Even as the traditional model has continued to have theoretical and practical influence, a succession of new forces has emerged. As the twentieth century nears its end, these have intensified into a confusion of possibilities, including modernism and postmodernism, deconstruction, neostructuralism, the rediscovery of ethnic traditions, and other trends as yet unnamed. Architectural practice has also moved away from monumentality to encompass less imposing structures such as the apartment complex and the shopping plaza. The perimeter of architecture has expanded beyond separate buildings to embrace urban groupings, such as the cultural center and the pedestrian mall. And it has enlarged its scope still farther, redeveloping urban zones into "cities" that incorporate apartments, offices, shops, schools, and parks. Moreover, the range of architecture has moved in a contrary direction to accept a structure that was once considered too lowly to be allowed into the elevated domain of grand art--the private dwelling. Domestic architecture has become an important genre, providing an opportunity to display new theories and innovative designs.

Along with expansive forces, integrative ones have been at work. We have become more aware of the physical and social context of a building, of the relation of its height, mass, and facade to nearby structures. Physical connections have begun to appear, too, such as second story walkways that join buildings above the street level and provide enclosed pedestrian pathways, binding separate structures and independent businesses into a network, an urban complex. This is also a sign of the increasing recognition of architecture's social role and function. Could we be moving, in the manner of Soleri's arcologies, toward total, integrated urban structures?

Such a multiplicity of tendencies reflects the present ambiguity of architectural art and, at the same time, our own equivocal position in its historical process. Perhaps we are caught in the decline and dissipation of an exhausted tradition. Perhaps we are trapped between the solutions of an irrelevant past and the irresolutions of 
an indeterminate future. Possibly we stand at the brink of a new view of the human world. These confusing directions offer an opportunity to reconsider the axiomatic principles of architectural theory, in particular, to articulate certain theoretical assumptions behind the expansive and integrative impulses in contemporary architecture. By stating what may have been felt only implicitly, we may discover both a key and a guide to the transformation of architecture and, as a consequence, of our entire built world.

\section{Integrating Distinctions and Oppositions}

The usual practice of critical inquiry is to develop distinctions and to comment on relationships among the factors that have been identified. Discussions of the arts typically note differences and draw contrasts, and this is particularly true in architectural theory and criticism. Like other distinctions, those in architecture tend to be expressed as oppositions: The facade is contrasted with the interior, the building with its site, architectural design with landscape design, decoration with utility, form with function, built areas with natural ones, and, the source of many of these distinctions, human needs and desires with natural processes. Architectural success is often measured by the ability to balance such opposing values and combine these dissonances into a harmonious whole.

Let us instead set this critical discussion in another direction, not discerning differences and opposing alternatives but identifying resemblances and developing continuities. That will make it easier to recognize the interrelations of various architectural factors and the interdependence of architecture with society and environment. It would be useful, for example, to reconsider the contrasts just cited by positioning them as distant points of a continuum, so that their resemblances and connections begin to emerge in place of the conceptual order of oppositions. A facade, for example, can set the tone for the decorative features, forms, and spaces of the interior, instead of being taken merely as a shell preserved for historical or other external reasons, a coating calculated to evoke associations of rev- 
erence, tradition, or scientific progress, or merely as a sensuous surface. And there are ways of merging the interior with what is beyond it by using glass walls, extending the roof or the floor plane, furnishing enclosed spaces with planters that bring the vegetation indoors, or using a form that embraces its site.

We can even discard the time-honored opposition of utility and beauty by recognizing that it is embedded in an aesthetic that rests more on philosophical history than on architectural experience. The contemplative aesthetics of the eighteenth century codified the classical distinction between theoretical and practical knowledge into a separation of beauty and use, the latter bound up with purpose, the former independent of utility. Architectural theory echoed that division by keeping structural demands entirely apart from aesthetic considerations. One response to this isolation of beauty from practice has been to think that function alone automatically achieves beauty of a kind. Sometimes, as in brutalism, it led to the assumption that directly reflecting the materials and structure of a building ensures its aesthetic value. The division of beauty and use, or the assimilation of the aesthetic to the practical, seems rather naive now, the triumph of a technological mentality more simple in conception than satisfactory in execution. Indeed, both brutalism and its decorative contrary, Beaux Arts architecture, implicitly accept the ideal of a universal standard, itself a pillar of traditional aesthetics and exemplified most powerfully in this century by the international style. Many of these ideas and movements stand at different points in the modernist tradition, which is itself a direct outgrowth of the eighteenth- century aesthetic.

A growing force in the twentieth century, however, has been the recognition of different ways in which beauty and use are inseparable. One of these lies in the unity of the practical and the aesthetic that is typical of vernacular architecture. Another is a new awareness of the beauty inherent in finely crafted objects of practical function, whether they are the product of a long cultural tradition or the deliberate accomplishment of a modern artisan. The influence of a craft aesthetic appears in the designs of Mies van der Rohe, I. M. Pei, and Fumihiko Maki; in the writings of Christopher Alexander; and in the work of others influenced by these figures. ${ }^{2}$ 
Another distinction that is beginning to be displaced is that between a building and its site. The concept seems obvious enough, but it has taken architects a long time to recognize the site-specific nature of good architecture. The history of architecture holds outstanding examples of this, but only recently has it come to be broadly recognized as a general precept. Two early modern architects who realized the intimate relation of building and site were Frank Lloyd Wright and Julia Morgan. Wright is well known for his sensitive application of this principle, and Morgan was a nineteenth-century American architect whose Asilomar Conference Center on the California coast blends its buildings with an uneven site populated by high pines. Standardized designs that have been imposed thoughtlessly on the landscape, from the rectangular block skyscraper to the ubiquitous ranch house, are being replaced by more imaginative and complex shapes that echo landforms and regional traditions, by embellishment that uses historical and regional motifs, and by local building materials that mirror the land.

The sensitivity of architecture to site is a powerful integrative force. It recognizes that a building is not self-sufficient or self-contained but both influences and is influenced by what surrounds it. Ways of joining structure and site include using indigenous species for foundation plantings and other landscaping, and emulating not only the physical and geological aspects of the location but also the buildings that stand nearby. We can extend the reciprocity of building and site to the neighborhood, to pedestrian and vehicular patterns, and eventually to the entire built complex of which the individual building is a constituent. When a building is not related to its physical and social context, the effects may vary from indifference to alienation and even outright hostility.

Underlying many of these customary oppositions is a difficulty in grasping the relation that human beings have to the natural world. Whereas indigenous peoples develop architectural forms and other cultural adaptations that reflect the connections, indeed the continuities, of their activities with natural forces, many intellectual, religious, and cultural traditions have found here, instead, profound discord. A separation of some sort between nature and what is 
distinctively human--a separation sometimes sharp enough to be seen as a conflict--developed in Hindu and Christian doctrine and in much of classical Greek and Hellenistic philosophy. The beliefs and practices that developed from these doctrines inherited this acquired characteristic. Moreover, this separation of the human and the natural has combined with modern science and technology and with the ever-increasing commercialism of an industrializing world to become a dominant feature of the contemporary scene. Yet this attitude is beginning to shift. Recent social and political movements, particularly the environmental movement, are rethinking conventional beliefs and values and working to reconcile this opposition of human and natural worlds. These are important signs of a change in the prevailing view. The conflict between these alternative ways of understanding the relationship of human and environmental interests will likely increase as we recognize more vividly how the environmental effects of our actions in turn affect ourselves.

From a larger perspective, however, we can see these separations as an aberrant development in the history of human habitation. For most of that history, an intimacy existed between humans and the natural world. People acted in and on their environment with care and respect. A dependence on natural factors led them to proceed, not from a sense of power over an alien world, but from an awareness of harmony with a place that was part of themselves. Alternative traditions and ideas reflected this sensibility. Taoism, Zen Buddhism, and natural theology are religions that bind people to nature. The pre-Socratics, Spinoza, Schelling, Emerson, Thoreau, and Dewey are philosophical thinkers for whom this connection is basic. In the latter part of the nineteenth century and throughout the twentieth, philosophic movements such as positivism, evolutionism, naturalism, and pragmatism sought to embody a similar insight. The endeavor to reintegrate human and nature has become increasingly influential. What is most significant about the instances of separation and opposition mentioned earlier is that such divisions are neither given nor necessary. Conceptualizing the human world through connections and continuities offers an alternative and leads to a different 
paradigm for architecture, one of relatedness and unity. Can we extend this model to other, still broader contexts and relationships?

\section{The Architecture of City and Environment}

The conventional distinction between architecture and the city is clear enough:

Architecture concerns the design of individual structures, whereas the city is the coherent collection of such structures. Even though such a distinction may appear obvious, the resemblance between architecture and the city is striking. The same concepts of mass, space, and volume help order the configurations of both. Both respond to considerations of human movement and use, and both offer a qualitative environment of surfaces, textures, colors, and light that affect not only our visual sensibility but also our tactile and especially our kinesthetic awareness. Architecture and city not only display parallels; they cannot be kept apart. If the aesthetic of a building can be extended to include its site, its site is affected by contiguous sites, just as a structure cannot usually be regarded in isolation but is apprehended in relation to its neighbors. Indeed, as we expand the range of our perception, the building becomes part of an entire district, and this, in turn, of the city.

Architectural experience, then, is a microcosm of urban experience. The perception, the dynamics, the function of architecture are all mirrored in the larger built environment we call the city. And in reciprocal fashion, we can grasp urban experience as architecture 'writ large.' Streets are urban corridors, gateways are doors, plazas are urban rooms for social intercourse, and houses are areas reserved for private activity. Our customary practices affect the temperature, the air, the very climate of a city, just as they do the atmosphere of a home or a building. It could be argued that the most representative architectural form of the collective mass culture of the postindustrial age is the city. This is the quintessential human landscape, and the same basic principles of coherence and context apply here as to an individual structure. Although the scale is vastly greater and there are emergent qualities in a city that a building does not possess, the central concepts are remarkably alike and the dynamic 
of their function very much the same. In fact, as buildings become more cohesive and their structures more contiguous, the line between city and building will be hard to locate and may eventually disappear.

Does the city define the limit of the built environment or can the connections, the continuity of building and city be carried further? What about the city's place in the landscape? Isn't the city a part of the region in which it is situated in more than a geographical sense? These are interesting questions for an aesthetics of continuity. Let us consider them in two ways: first by exploring the parallels between the city and the larger landscape, and then by examining their connections and boundaries.

It is curious how far one can go in applying architectural features to the landscape. If imagination is given some license, we can see the landscape as exhibiting a surprising number of architecture-like elements. Roads are corridors; turnoffs and drives are entrances and exits. Fields, meadows, and glades--whether bounded by stone walls, fences, hedges, or ditches or merely by texture, contents, or function--are rooms in the landscape and, like rooms, possess as much character as their owner or other influences may give them. We often speak of the height of the cloud cover as a ceiling, and a break in the clouds through which sunlight streams can be seen as a celestial skylight. The ground becomes a floor, a trail through dense growth a hallway; a mounting path resembles a stairway, an overlook a balcony, the swerve of a grassy bank an amphitheater, a border of trees a wall, and the concave curve of the sky a dome. It is remarkable how often we metaphorically assign the names of building elements to features of the landscape, and the parallel can as easily be drawn in the reverse direction. Sunken living rooms, for example, emulate the protective hollow or valley, as the groins in the vaulting of cathedral ceilings mirror the canopy of branches in a grove. One could construct a veritable homology between architecture and landscape.

How does it change our perception of an environment to recognize its similarities to a house or a building? How does it change our perception of a building to regard it not in opposition to environment but in imitation of it? As our understanding widens here, 
so perhaps does our perception, until we may dwell in the landscape, as Heidegger would have it, and see our home as a landscape and the landscape as our home.

Beyond the architecture of environment, there are other connections between city and landscape that transgress old boundaries. The sharp lines and distinct colors on a map that define the extent of cities are as insubstantial as the walls that once bounded medieval cities are today. The first are cartographic fictions; the second survive mostly as historical curiosities. We can no longer clearly identify the physical perimeter of a city. It spreads out from its center with decreasing density, until commercial and industrial pockets and corridors merge with agricultural areas or uncultivated terrain. Metropolitan spread has absorbed vast regions of the eastern and western seaboards of the United States. Where cities once had protective boundaries, there is now neither boundary nor protection.

It is well to remember that just as the concept of a landscape is a human construct, the landscape as a geographical area is a human construction. Our actions have not only shaped inhabited landscapes but also irreparably changed those that are no longer and perhaps never were inhabited. During the same time that the wilderness lost its fearful mystery and awe (that is, by the latter part of the eighteenth century) the industrial domination of the landscape began in earnest and the idea of primeval wilderness became a literary fiction. ${ }^{3}$ "Knowledge is power," Francis Bacon had proclaimed at the beginning of modern science. Scientific knowledge meant power over nature, and the impulse to impose the one's will--so characteristic of half-civilized individuals and societies--was partially sublimated into the domination of nature. But the battle takes subtler form here in the landscape, and the consequences are delayed and indirect. As in so many other cases of conflict, the opposition of human and nature is not clearly drawn, and their forces not separable. Nature is not out there, a place apart from us. We have, instead, a continuity of humans and natural world. What we need now is to reconceptualize our world in a way that comes to terms with this, for what we do in environment we do to ourselves--to the ssame air we breathe into our bloodstream, to the 
same water that is the liquid of our life, to the same earth whose fruits become our body.

\section{The Earth Is My Body}

We can now see the fallacy in architecture's conventional wisdom that "the ultimate task of architecture is to act in favor of man: to interpose itself between man and the natural environment in which he finds himself." ${ }^{4}$ This seemingly incontrovertible axiom, which James Marston Fitch took as the fundamental thesis of his major study of American architecture, is especially surprising for a commentator whose sensitivity to the experiential factor in architecture was exemplary. ${ }^{5}$ Yet it testifies to the deep-rooted strength of the belief. Now, however, we can rephrase the mission of architecture by transposing that axiom onto a new plane: the ultimate task of architecture is to act in favor of the human environment by mediating the reciprocity of people and the landscape that is their natural home. This is a far more complex task than designing shelters against the wilderness, a far more sophisticated undertaking than building edifices. The architect must now go beyond being alternately a materials and structural engineer, a designer, and even an applied artist. Perhaps we should return to the medieval practice of architecture as a collective art and employ the expert services of the ecologist, the environmental psychologist, the cultural geographer, the anthropologist, the landscape architect, the urban and regional planner, the environmental artist, and the aesthetician, in addition to the engineer, the designer, and the architect.

Instead of an opposition between human and nature, then, we must grasp their continuity. Instead of architecture imposing itself on the landscape or even responding to the landscape, perhaps we can invert the order and encourage architects to take environment as their model. Their task would then be to fashion structures that do not interpose themselves between humans and the natural environment, that do not even mediate between them, but that respond to and articulate the continuities that bind people to their landscape, a landscape that makes them human--a humanized landscape, a naturalized humanity. 
For our culture of opposition, aggression, and defensiveness, this is a difficult task. It is understandable how sensitive commentators, presented with this scene, look to architecture for protection. Bachelard, the poet of space, regarded the house as "a tool for analysis of the human soul.... Our soul is an abode. And by remembering 'houses' and 'rooms,' we learn to 'abide' in ourselves." ${ }^{6}$ Although houses and rooms do possess an intimate bond with ourselves, Bachelard saw the self as subjectivity, and this led him to subjectify space and to an aesthetics of withdrawal. Yet we find ourselves intimately connected to the rooms and houses we inhabit precisely because we cannot separate our selves from them. We see ourselves in the houses of our childhood; they contribute to the selves that we are; we become ourselves in and through those places. Here, in the heart of withdrawal, is the very continuity, that fusion of self and place, of which I have been speaking. That fusion, however, does not end at the outside wall. Even Levinas, who, like Bachelard, accepted a division of inner and outer and regarded the home as an inwardness, an interiority, also recognized that it borders on an exteriority. The private domain of one's being opens out to the world. Yet we now see an alternative to this defense of the self by separation and insulation. We must move beyond the architecture of refuge to an architecture of continuity.

The special accomplishment of writers whose work centers on particular regions lies not just in their ability to convey a sense of the character and distinctiveness of these areas but also in their ability to locate human identity in them. What they impart has more than autobiographical interest. The appeal is universal, for it exemplifies how a person is formed in the human and natural landscape. We learn from Wendell Berry's essays on Kentucky, Barry Lopez's travels in the Arctic and the desert, Ivan Doig's reminiscences of Montana about a kind of connection with landscape that we know in our bones but have not articulated, an inheritance more direct and more powerful than anything genetic. ${ }^{7}$ Writers like these help us discover a sense of home that is often obscured by the impersonality of mass culture and standardized architecture, a home that is the fusion of person and place. If our obsession 
were more with places than with genes, we might be more successful in discovering who we are in where we are.

We come by various routes, then, to an overarching union of people, architecture, and landscape. Connections hold, not divisions; continuities, not separations. The architectural structure is bonded, on the one hand, to its inhabitants and, on the other, to its site, neighborhood, town or city, and region, and eventually, by influences that range from the climatic to the cosmic, to the universe. This is the ultimate integration of the architectural and the human: In continuity lies identity. 


\section{NOTES}

1. See Paul Oskar Kristeller, "The Modern System of the Arts," in Renaissance Thought, rev. \& enl. ed., Vol. 2 (New York: Harper, 1961), pp.163-227.

2. See Christopher Alexander, A Pattern Language (New York: Oxford University Press, 1977) and A New Theory of Urban Design (New York: Oxford University Press, 1987). Other architects who, in different ways, unite the practical and the aesthetic include the contemporaries Frank Gehry, especially his Walt Disney Concert Hall, the New Mexico "ecology" architect Michael Reynolds, who uses recycled materials and solar energy, and the Arkansas architect E. Fay Jones, whose Thorncrown Chapel in Eureka Springs, Arkansas merges architecture and landscape.

3. Keith Thomas documents this change in attitude in Man and the Natural World (New York: Pantheon, 1983).

4. James Marston Fitch, American Building, 2nd ed., 2 vols., (Boston: Houghton, Mifflin, 196672), p.1.

5. See James Marston Fitch, "The Aesthetics of Function," Annals of the New York Academy of Sciences, 128,2, 706-714 (Sept. 27, 1965).

6. Gaston Bachelard, The Poetics of Space (New York: Orion, 1964), p.xxxiii. Appleton's widely cited prospect-refuge theory of landscape experience illustrates the continuing influence of a dualistic architecture of protection exported to environment. See Jay Appleton, $\underline{\text { The }}$ Experience of Landscape (London and New York: Wiley, 1975). 
7. Wendell Berry, The Long-legged House (New York: Harcourt, Brace \& World, 1969; Barry Lopez, Arctic Dreams, Imagination and Desire in a Northern Landscape (New York: Scribner's, 1986), and Desert Notes (Kansas City: Andrews and McNeel, 1976); Ivan Doig, This House of Sky; Landscapes of a Western Mind (New York \& London: Harcourt, Brace, Jovanovich, 1978). 